\title{
Prevalence of Type 2 Diabetes Mellitus in patients with Chronic Liver Disease
}

MD. KHAIRUL ISLAM, ${ }^{1}$ MOSTOFA KAMAL CHOWDHURY, ${ }^{1}$ HAM NAZMUL AHASAN, ${ }^{2}$ PRODIP KUMAR BISWAS ${ }^{3}$

\begin{abstract}
Background and Purpose: The development of type 2 diabetes mellitus (T2DM) is caused by a combination of genetic factors and lifestyle factors like obesity, lack of physical activity and stress. T2DM can develop in chronic liver disease (CLD) though its actual mechanism is not fully understood. In case of hepatitis $B$ virus $(H B V)$ related CLD, HBV infection has been directly related to development of abnormal glucose metabolism by pancreatic islets cell injury. Development of Insulin resistance in case of hepatitis C virus (HCV) is the key pathogenesis of development of type 2 diabetes. We aimed to study the magnitude of the problem of T2DM among the patients with various types of CLD and to find out the association of diabetes mellitus with the demographic and clinical characteristics of the patient admitted in Medicine ward in Dhaka Medical College Hospital.

Methods: This was an observational cross sectional study of 60 patients admitted into department of Medicine, Dhaka Medical college hospital between June, 2013 to December, 2013. It included all patients $\geq 18$ years of age and admitted with CLD.A diagnosis of CLD was made clinically by any 2 stigmata of liver disease and biochemical, ultrasonographic, endoscopic evidence of esophageal varices \pm liver biopsy.

Results: Of the total 60 CLD patients, 40 (66.7\%) suffered from chronic HBV infection, I I (I8.3\%) chronic $\mathrm{HCV}$ infection and alcoholic liver disease 5 (8.3\%), Autoimmune I (I.7\%), Wilson disease I (I.7\%) and unknown cause were 2 (3.3\%). Among the study subjects $21.67 \%$ had overt Diabetes Mellitus and it was found to be highest among those with chronic hepatitis C (36.4\%) and those with chronic hepatitis B (20\%) alcohol (20\%). Type 2 DM was significantly higher among the CLD patients aged more than 50 years or more.

Conclusions: It can be concluded that the occurrence of diabetes and impaired glucose tolerance (IGT) could be a matter of great concern in CLD patients, indicating towards the need for regular monitoring of the glycemic status in these patients, which would have a definite role upon the treatment strategy.
\end{abstract}

Keywords: Type 2 diabetes mellitus, chronic liver disease, chronic hepatitis.

\section{Introduction:}

Diabetes that develops as a complication of chronic liver disease is known as "hepatogenous diabetes." 1,2 Patients acquiring diabetes as a result of cirrhosis of liver differ from typical type 2 diabetes mellitus patients by having a lower prevalence of family history of diabetes and a lower risk of macro and micro angiopathic complication. ${ }^{1}$ In a point prevalence study, the prevalence of micro and peripheral macro angiopathy and coronary heart disease in cirrhosis with diabetes mellitus was comparable to that of controls, and was significantly lower than that observed in randomly

1. Indoor Medical Officer, Department of Medicine, Dhaka Medical College Hospital, Dhaka.

2. Professor, Department of Medicine, Popular Medical College Hospital, Dhaka.

3. Associate Professor, Department of Medicine, Dhaka Medical College Hospital, Dhaka.

Corresponding author: Dr. Md. Khairul Islam, Indoor Medical Officer, Department of Medicine, Dhaka Medical College Hospital, Dhaka, Bangladesh. Mob no. 01717696207. selected patients with T2DM. ${ }^{3}$ Numerous reports in the literature have indicated that impaired glucose tolerance (IGT) and diabetes mellitus (DM) frequently complicate chronic viral hepatitis and cirrhosis. In patients with cirrhosis of liver, the prevalence of IGT is estimated to be about 60$80 \%$, and that of overt diabetes is about $7-15 \%$. 4,5

More than 171 million people globally are affected by DM, and the figure is expected to rise up to 366 million by 2030 . $^{6}$ T2DM in South Asian, when comparing with European individuals, is 4 - to 6 -fold more prevalent. ${ }^{7} \mathrm{DM}$ is characterized by recurrent or persistent hyperglycemia, and is diagnosed by demonstrating any one of the following: ${ }^{8}$

- Fasting plasma glucose level $\geq 7.0 \mathrm{mmol} / \mathrm{l}(126 \mathrm{mg} / \mathrm{dl})$

- Plasma glucose $\geq 11.1 \mathrm{mmol} / 1$ (200 mg/dL) two hours after a $75 \mathrm{~g}$ oral glucose load as in a glucose tolerance test

- Symptoms of hyperglycemia and casual plasma glucose $\geq 11.1 \mathrm{mmol} / 1(200 \mathrm{mg} / \mathrm{dl})$

- Glycated hemoglobin (Hb A1C) $\geq 6.5 \%$. 
A positive result, in the absence of unequivocal hyperglycemia, should be confirmed by a repeat of any of the above methods on a different day. The Expert Committee on the Diagnosis and Classification of Diabetes Mellitus defined Impaired fasting glucose (IFG) as fasting plasma glucose levels between 100 and $125 \mathrm{mg} / \mathrm{dL}$ (between 5.6 and $6.9 \mathrm{mmol} / \mathrm{L}$ ) and IGT as 2-h PG after 75-g OGTT levels between 140 and $199 \mathrm{mg} / \mathrm{dL}$ (between 7.8 and $11.0 \mathrm{mmol} /$ L). It should be noted that the World Health Organization (WHO) and numerous other diabetes organizations define the IFG cutoff at $110 \mathrm{mg} / \mathrm{dL}(6.1 \mathrm{mmol} / \mathrm{L}){ }^{8}$

Liver is one of the vital and largest organs of the body. The clinical manifestations of liver injury are diverse- ranging from isolated and clinically silent laboratory abnormalities to dramatic and rapidly progressive liver failure. Association of diabetes mellitus with chronic liver disease has been recognized for over 2 decades and there is also evidence that diabetes have a higher association of chronic viral hepatitis $\mathrm{B}$ and $\mathrm{C}$ related cirrhosis than the normal population. ${ }^{9}$

Hepatitis B virus infection has been directly related to the development of glucose metabolism disorders secondary to pancreatic islets cell injury. ${ }^{10}$ A recent study from the 3rd National Health and Nutrition Examination Survey (NHANES -III) in United States reported a threefold greater risk of type 2 diabetes in $\mathrm{HCV}$ positive more than 40 years old subjects, compared to those who were HCV negative. ${ }^{11}$

Several studies reported that HCV infection may also contribute to the development of diabetes, and higher prevalence of type 2 diabetes mellitus has been observed in the developed world ( $2 \%$ to $9.4 \%)$ in patients with $\mathrm{HCV}$ infection than in those with other forms of chronic hepatitis. ${ }^{12-15}$ This association between HCV infection and diabetes was for the first time made by Allison et al. in 1994. ${ }^{16}$ Since then, a number of observational studies have been published.

There are several organized factors which influence the development of diabetes among HCV-infected patients like age, sex, family history of diabetes, African -American race, and HIV co- infection. ${ }^{17,18}$ Insulin resistance (IR) and diabetes can develop at any stage of HCV infection. Multiple mechanisms have been accounted for insulin resistance and development of diabetes in patients with chronic hepatitis C. It promotes IR mainly through interfering with insulin signaling pathway in hepatocytes, increasing inflammatory response with production of cytokines such as TNF alpha and IL-6 and increasing oxidative stress. ${ }^{19}$
Recently in a medical college in Kolkata, a cross sectional study on occurrence of type 2 diabetes mellitus among the patient with $\mathrm{CLD},{ }^{20}$ among the study subjects, $58.1 \%$ had IGT while $14 \%$ had overt DM. IGT and diabetes were significantly higher among that CLD patients aged 45 years or more $(\mathrm{p}<0.05)$. However, similar association was not observed with regard to sex of the patients. No association was found between the occurrence of overt diabetes with either severity as per Child Pugh score or duration of CLD. Another study was conducted in King Fahad Central Hospital, Saudi Arabia regarding prevalence and factors affecting occurrence of T2DM. ${ }^{21}$ Here Ashwani K, et al. concluded that patients with $\mathrm{HCV}$ related disease had a higher prevalence of T2DM compared to HBV related disease, their difference was not significant (26.3 vs $15.7 \%$; $<<0.05$ ). A strong association has been found between HCV and DM. Patient with chronic hepatitis $\mathrm{C}$ have an increased risk of insulin resistance \& type 2 DM (Knobler, et al. 2000). ${ }^{22}$

$\mathrm{Li}$, et aI. conducted a hospital-based case - control study to evaluate the role of T2DM in hepatocellular carcinoma (HCC) development in patients with CHB from January 2004 to December $2008 .^{23}$ The prevalence of Type 2 diabetes is higher among HCC patients without cirrhosis than among those with cirrhosis $(12.1 \%$ vs. $6.7 \%, \mathrm{p}=0.003)$. T2DM was associated with a significantly high risk of HCC in female patients after adjusting for age, family history of $\mathrm{HCC}$, city of residence, hepatitis B e antigen and cirrhosis with an odds ratio $(95 \%$ confidence interval, $\mathrm{Cl}$ ) of $1.9(1.1-3.4)$. Restricted analyses among female patients without cirrhosis indicated that Type 2 diabetes was strongly associated with HCC risk with adjusted odds ratio $(95 \% \mathrm{Cl})$ of $5.6(2.2-$ 14.1). In conclusion, Type 2 diabetes is independently associated with the increased risk of HCC in female CHB patients. Female CHB patients with Type 2 diabetes are of a high HCC risk population and should be considered for HCC close surveillance program. ${ }^{23}$

Caronia, et al. 1999 found that the prevalence of DM was higher in HCV-related cirrhosis (23.6\%) than in HBV-related cirrhosis $(9.4 \%$; odds ratio [OR]. 2.78: 95\% confidence interval $[\mathrm{Cl}], 1.6-4.79 ; \mathrm{P}=0.0002) .235$ patients with biopsy confirmed chronic HBV or HCV underwent an oral glucose tolerance test. Only 1 of 70 patients with chronic viral hepatitis without cirrhosis was diabetic. However, 31 of 127 patients with HCV-related cirrhosis (24.4\%) were diabetic compared with 3 of 38 patients with HBV related cirrhosis $(7.9 \%, \mathrm{p}=0.048)$. The major variables associated with NIDDM were cirrhosis (OR, 14.39; 95\% Cl, 1.91-108; $\mathrm{P}=$ $0.096)$ and male sex (OR, 4.64; $95 \% \mathrm{Cl}, 1.32-16.18$ : $\mathrm{P}=0.161$ ). Fasting insulin levels in 30 patients with HCV- 
related cirrhosis and diabetes mellitus were elevated significantly, which was consistent with insulin resistance. However, acute insulin responsiveness was reduced in all patients with $\mathrm{HCV}$ infection and diabetes suggesting concomitant B-cell dysfunction. This study confirms an association between HCV and NIDDM. ${ }^{24}$

Younossi et al. investigated the prevalence of DM among the patients of non-alcoholic steato hepatitis (NASH). They showed Of 132 patients with non-alcoholic fatty liver disease (NAFLD), 44 patients (33\%) had an established diagnosis of DM. Patients with NAFLD and DM are at risk for the development of an aggressive outcome, such as cirrhosis and mortality. ${ }^{14}$

In a study at BIRDEM hospital of Dhaka, newly detected DM \& IGT patient with elevated serum Alanine Transaminase (ALT) level was found in $8.33 \%$ case of HBsAg seropositivity in contrast to $4.17 \%$ case of anti-HCV seropositivity. Though $76.67 \%$ was NAFLD, this study reported that $3.33 \%$ had both NAFLD \& HBsAg seropositivity. $^{25}$

CLD and type 2 diabetes mellitus are two chronic conditions which contribute to a significant morbidity and mortality. Literature is scarce regarding the occurrence of type 2 diabetes mellitus in CLD in Bangladesh. The involvement of liver in DM is well studied, but the prevalence of T2DM in CLD patients not known to be diabetic, has not been well studied. Hence present study was conducted in Dhaka medical college hospital with the objectives to study the magnitude of the problem of type 2 diabetes mellitus among the patients with various types of CLD, to find out the association of DM with the demographic and clinical characteristics of the patients.

\section{Materials and Methods:}

This was an observational cross sectional study of 60 patients admitted into Dhaka Medical College Hospital, Dhaka, from June 16, 2013 to December, 2013. Patients admitted with chronic liver disease in Medicine unit, Dhaka Medical College Hospital were included in this study. It included all patients $\geq 18$ years of age with chronic liver disease, not known to be diabetic previously or not taking any drugs (like thiazides, steroid, interferon etc.) that may lead to the development of IGT. A diagnosis of CLD was made clinically by any 2 stigmata of liver disease and biochemical features suggestive of cirrhosis of liver and ultrasonographic evidence of coarse echo texture of liver parenchyma and/or endoscopic evidence of esophageal varices and liver biopsy. Confidentiality was assured and anonymity maintained. Data was collected by structured questionnaire from voluntarily participated individuals.

\section{Result:}

Total 60 cases of CLD were selected. The sample population included $48(80 \%)$ male and $12(20 \%)$ females with ages ranging from 18 to 70 years. Highest numbers of cases (24) were from 51-60 years age group. Regarding the occupational status, most were businessman $(23.3 \%)$ in profession followed by $18.3 \%$ housewives (Table - I). Of the total 60 CLD patients, $40(66.7 \%)$ suffered from chronic hepatitis B (HBV) infection followed by $11(18.3 \%)$ chronic hepatitis $\mathrm{C}$ (HCV) infection (Table - II). Combinations of different clinical features were observed in patients with chronic liver disease. The most common presentations were abdominal swelling due to ascites (66.67\%) and Jaundice (45. 9\%) (Table - III). The highest prevalence of DM and IGT among the patients with chronic liver diseases (CLD) was found in the 51-60 years age group (Table - IV). It was observed that $37.5 \%, 27.3 \%, 60 \%$, of the patients with chronic liver disease due to chronic hepatitis $\mathrm{B}$, chronic hepatitis $\mathrm{C}$, alcoholic liver disease respectively had IGT. On the other hand occurrence of overt diabetes was found to be highest among those with chronic hepatitis $\mathrm{C}(36.4 \%)$ in comparison to chronic hepatitis B (20\%) alcohol (20\%) (Table - V). Only $20 \%$ had family history of DM whereas $80 \%$ of study subjects had no family history (Fig 1). Among the newly diagnosed cases of DM with CLD patients $(n=13)$ family history of DM was present in $38.47 \%$ and $61.53 \%$ had no family history (Table-VI).

Table - I

Demographic characteristics of study subject $(n=60)$

\begin{tabular}{lcc}
\hline Characteristics & Frequency of CLD & Percentage (\%) \\
\hline Age & & \\
- $\quad 18-30$ & 3 & $5.0 \%$ \\
- $\quad 31-40$ & 10 & $16.7 \%$ \\
- $\quad 41-50$ & 16 & $26.7 \%$ \\
- $\quad 51-60$ & 24 & $40.0 \%$ \\
- $\quad 61-70$ & 7 & $11.7 \%$ \\
Gender & & \\
- Male & 48 & $80.0 \%$ \\
- Female & 12 & $20.0 \%$ \\
Profession & & \\
- $\quad$ Businessman & 14 & $23.3 . \%$ \\
- Service holder & 7 & $11.7 \%$ \\
- Teacher & 4 & $6.7 \%$ \\
- $\quad$ Driver & 4 & $6.7 \%$ \\
- House wife & 11 & $18.3 \%$ \\
- Farmer & 9 & $15.0 \%$ \\
- $\quad$ Others & 11 & $18.3 \%$ \\
\hline
\end{tabular}


Table - II

Aetiology of chronic liver diseases $(n=60)$

\begin{tabular}{lccc}
\hline Causes of CLD & Frequency & $\begin{array}{c}\text { Percent } \\
(\%)\end{array}$ & $\begin{array}{c}\text { Cumulative } \\
\text { Percent }(\%)\end{array}$ \\
\hline HBV & 40 & 66.7 & 66.7 \\
HCV & 11 & 18.3 & 85.0 \\
Alcohol & 5 & 8.3 & 93.3 \\
autoimmune & 1 & 1.7 & 95.0 \\
Wilsons & 1 & 1.7 & 96.7 \\
Unknown & 2 & 3.3 & 100.0 \\
Total & 60 & 100.0 & \\
\hline
\end{tabular}

Table - III

Clinical presentation of chronic liver diseases.

\begin{tabular}{lcc}
\hline Clinical presentation & \multicolumn{2}{c}{ Frequency of CLD } \\
& $\mathrm{N}$ & Percentage (\%) \\
\hline Vomiting of blood & 17 & 28.33 \\
Melaena & 14 & 23.80 \\
Ascites & 40 & 66.67 \\
Jaundice & 27 & 45.09 \\
Confusion & 13 & 21.71 \\
Asymptomatic & 1 & 1.67 \\
\hline
\end{tabular}

Table - IV

Glycemic status according to age group.

\begin{tabular}{lcccccc}
\hline Age of patient & \multicolumn{2}{c}{ Euglycaemic } & IGT & DM & \\
& Count & $\%$ & Count & $\%$ & Count & $\%$ \\
\hline $18-30$ & 2 & 7.7 & 1 & 4.8 & 0 & 0 \\
$31-40$ & 6 & 23.1 & 3 & 14.3 & 1 & 7.7 \\
$41-50$ & 7 & 26.9 & 7 & 33.3 & 2 & 15.4 \\
$51-60$ & 7 & 26.9 & 8 & 38.1 & 9 & 69.2 \\
$61-70$ & 4 & 15.4 & 2 & 9.5 & 1 & 7.7 \\
\hline
\end{tabular}

Table - V

Glycemic status of the study subjects as per etiology of chronic liver disease

\begin{tabular}{lcccccc}
\hline Aetiology & \multicolumn{2}{c}{ Euglycaemic } & \multicolumn{2}{c}{ IGT } & \multicolumn{2}{c}{ DM } \\
& Count & $\%$ & Count & $\%$ & Count & $\%$ \\
\hline HBV $(\mathrm{n}=40)$ & 17 & $42.5 \%$ & 15 & $37.5 \%$ & 8 & $20.0 \%$ \\
HCV $(\mathrm{n}=11)$ & 4 & $36.4 \%$ & 3 & $27.3 \%$ & 4 & $36.4 \%$ \\
Alcohol $(\mathrm{n}=5)$ & 1 & $20.0 \%$ & 3 & $60.0 \%$ & 1 & $20.0 \%$ \\
Autoimmune $(\mathrm{n}=1)$ & 1 & $100.0 \%$ & 0 & $0.0 \%$ & 0 & $0.0 \%$ \\
Wilson Disease $(\mathrm{n}=1)$ & 1 & $100.0 \%$ & 0 & $0.0 \%$ & 0 & $0.0 \%$ \\
Unknown (n=2) & 2 & $100.0 \%$ & 0 & $0.0 \%$ & 0 & $0.0 \%$ \\
\hline
\end{tabular}

Table - VI

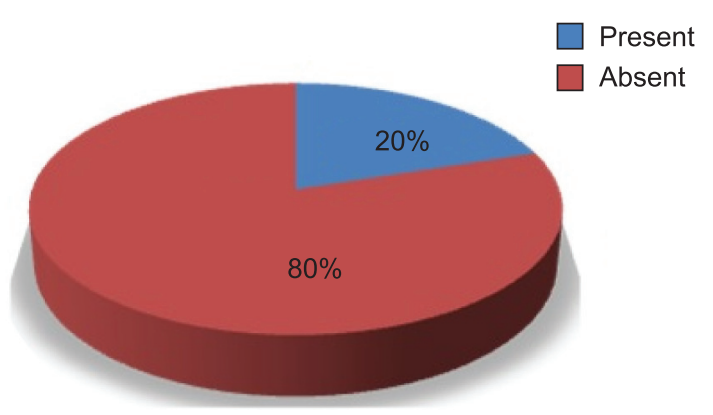

Fig 1: Family history of DM among the study subjects.
Family history of DM among the patients of CLD with newly diagnosed DM $(n=13)$.

\begin{tabular}{lcc}
\hline Family history & $\begin{array}{c}\text { Number cases of } \\
\text { CLD with DM }\end{array}$ & $\begin{array}{c}\text { Percent } \\
(\%)\end{array}$ \\
\hline Present & 5 & $38.47 \%$ \\
Absent & 8 & $61.53 \%$ \\
\hline
\end{tabular}

Discussion:

Association of diabetes with chronic liver diseases is not well studied in our country. But recent study reported a strong association between CLD and DM in Asian Americans, and 
this association remained statistically significant after adjustment for potential confounding variables. ${ }^{26}$ Their results suggested that CLD may be a potential risk factor for the development of DM among Asian Americans.

Diabetes mellitus itself may be a cause of liver disease, via non-alcoholic fatty liver disease (NAFLD), non-alcoholic steatohepatitis (NASH), cirrhosis and ultimately hepatocellular carcinoma. ${ }^{27}$ Conversely, diabetes and IGT develop quite frequently in chronic liver disease. ${ }^{28,29}$ The present study was conducted to get an idea about the occurrence of DM and/or IGT among the study subjects with chronic liver diseases due to various aetiologies and not known to be diabetic.

This hospital based observational study was carried out with an aim to determine the prevalence of T2DM among the patients of CLD and also to see the association of age, sex included occupation, family history in CLD patients with DM and IGT in our country. Total 60 case of chronic liver disease were selected; among them, 40 (66.7\%) suffered from chronic hepatitis B (HBV) infection, 11 (18.3\%) chronic hepatitis $\mathrm{C}(\mathrm{HCV})$ infection, alcoholic liver disease 5 (8.3\%), Autoimmune 1 (1.7\%), Wilson disease 1 (1.7\%) and unknown cause were 2 (3.3\%). In a recent study Mukherjee, et al. found that $74.3 \%$ alcoholic liver diseases, $14 \%$ had chronic hepatitis $\mathrm{B}$ infection and $6.6 \%$ hepatitis $\mathrm{C}$ infection. ${ }^{20}$ Compared to present study in Bangladesh alcoholic liver disease is significantly low may be due to religious bar. But due to previous sharing needle during injection and present habit of shaving and cutting hair in saloon may contribute to the very high incidence of chronic hepatitis B infection, compare to other cause of CLD. IGT was found to be quite high among the CLD patients in the present study for chronic hepatitis B 37.5\%, Chronic hepatitis C 27\% Alcoholic liver disease $60 \%$ it was very similar to Mukherjee et al. ${ }^{20}$ Those who were glucose intolerant were, therefore, at high risk of getting frank diabetes with the passage of time.

There is a wide range in the prevalence of type 2 diabetes in CLD patients in various studies. The frequency of overt diabetes has been reported across the globe in $30-60 \%$ case. $^{30}$ Alavian, et al. from Iran reported that out of the total 185 enrolled CLD patients IGT was found in $11.3 \%$ and overt diabetes in $21.6 \%{ }^{29}$ Another study Kobashsi et al. from Mexico reported nearly $23 \%$ prevalence of type 2 DM among the CLD patients. ${ }^{28}$ The present study revealed that prevalence of type 2 diabetes mellitus was $21.67 \%$ and which is very near to above well recognized studies.

In age group 51-60 years, highest prevalence of DM (69.2\%) was found in our study. Mason, et al. showed that the highest prevalence of diabetes mellitus in 5th decade and male female ratio was almost $4: 1 ;^{31}$ the findings regarding the age and sex incidence of the above study findings are consistent to current study. However, similar association is inconsistent regarding of sex of the patients according to Alavian, et al. ${ }^{29}$ that found a significant association of diabetes and IGT with older age but not with sex of the CLD patients.

The etiology of liver disease is important in the incidence of type 2 diabetes; NAFLD, alcohol, HCV, hemochromatosis and autoimmune hepatitis are more frequently associated with diabetes. ${ }^{17}$ According to aetiology of CLD, prevalence of type 2 diabetes very high in HCV which was $36.4 \%$. When we compared the prevalence of type 2 diabetes in $\mathrm{HCV}$ infected population with that of HBV it was $20 \%$, about twice. This higher rate of type 2 diabetes in HCV was consistent with Mason et al. where they reported diabetes in $21 \%$ in hepatitis $\mathrm{C}$ virus (HCV) infected patients as compared to $12 \%$ with hepatitis B virus infection. ${ }^{31}$ Qureshi et al. from Karachi, Pakistan reported an almost equal occurrence of diabetes in both HBV and HCV related liver disease. ${ }^{32}$

White, et al. analyzed 34 eligible retrospective and prospective studies, showing a significant risk of type 2 diabetes in $\mathrm{HCV}$-infected group as compared to non-HCVinfected control group. ${ }^{33}$ On the other hand, recent data also suggest three times higher prevalence of type 2 diabetes in HCV seropositive patients. ${ }^{34}$ In this way, data from the previous literature and from our study show a strong association between HCV and type 2 diabetes. Several reasons can explain the association of type 2 diabetes with $\mathrm{HCV}$. One of the explanations is that the pathophysiology of HCV-associated type 2 diabetes mellitus consists of a defect in insulin secretion, increased hepatic tumor necrosis factor alpha, excessive hepatic glucose production, and insulin resistance, because the core-encoding region of $\mathrm{HCV}$ is sufficient to induce insulin resistance by the previously defined mechanism via either direct or indirect way. ${ }^{35}$ Secondly, a major contribution of already present risk factors of diabetes such as positive family history and advancing age also plays an important role among $\mathrm{HCV}$ infected persons. ${ }^{36}$ Advancing age ( $\geq 40$ years) in HCV seropositive patients was significantly associated with type 2 diabetes mellitus as compared to younger age group ( $\geq 18$ to 40 years) on both univariate and multivariate analyses. The finding also agrees with another study conducted earlier on Mexican population. ${ }^{37}$

\section{Conclusion:}

There are some limitations in present study like lack of previous records of glycaemic status in few cases, small sample size, no regular follow up regarding glycaemia after 
discharge. This study showed that the prevalence of DM in CLD was $21.67 \%$. It indicates a high prevalence of DM in patients with CLD in Bangladesh. Most of the patients were in 4th to 5th decade with different occupation. Since a considerable number of diabetic patients were unaware of their problem, it is imperative that the patients should be screened for glucose intolerance periodically.

Conflict of interest: None.

\section{References:}

1. Holstein A, Hinze S Thiessen E, Plaschke A, Egberts EH, Clinical implications of hepatogenous diabetes in liver cirrhosis. J Gastrenterol Hepatol 2002;17:677 -81.

2. Picardi A, D'Avola D, Gentilucci UV, Galati G, Fiori E, Spataro S, et al. Diabetes in chronic liver disease: from old concepts to new evidence. Diabetes Metab Res Rev 2006;22:274-83.

3. Marchesini G, Ronchi M, Forlani G, Bugianesi E, Bianchi G, Fabbri A, et al. Cardiovascular disease in cirrhosis - a point prevalence study in relation to glucose tolerance. AMJ Gastroenerol 1999;94:655-62.

4. Perseghin G, Mazzaferro V, Sereni LP, Regalia E, Benedini $\mathrm{S}$ Bazzigaluppi E, et al. Contribution of reduced insulin sensitivity and secretin to the pathogenesis of hepatogenous diabetes: Effect of liver transplantation. Hepatology 2000;31:694 -703.

5. Tietge UJ, Selberg O, Kreter A, Bahr MJ, Pirlich M, Burchert $\mathrm{W}$, et al. Alterations in glucose metabolism associated with liver cirrhosis persist in the clinically stable long term course after liver transplantation. Liver Transpl 2004;10:1030 1040 .

6. Gul N. Knowledge, attitudes and practices of type 2 diabetic patients. Journal of Ayub Medical College, Abbottabad,2010;22(3):128 -131.

7. Rees SD, Hydrie MZI, O'Hare JP et al. Effects of 16 genetic variants on fasting glucose and type 2 diabetes in South Asians: ADCY5 and GLIS3 variants may predispose to type 2 diabetes. PLoS ONE 2011;6(9).

8. Definition of diabetes and intermediate hyperglycemia: report of a WHO/IDF consultation. World Health Organization. 2006. p. 21. ISBN 978 -92-4-159493-6.

9. Tolman K. G. fonseca, V.,Dalpiaz, A., Meng, H., The spectrum of liver disease in Type 2 diabetes mellitus and management of patients with diabetes and liver disease. 2007;30:734.

10. Shi DR, Dong CL, Lu L, Cong WT, Zhou Y, Relationship between glucose metabolic disorders and expression of insulin receptor in post hepatic cirrhosis hapatocytes and HBV DNA in pancreatic cells. Zhonghua Shi Yan He Lin Chuang Bing Du Xue Za Zhi. 2003;17:372-74.
11. Mehta SH, Brancati FL, Sulkowski MS, Strathdee, Thomas DL. Prevalence of type 2 diabetes mellitus among persons with hepatitis c virus infection in united states. Ann Intern Med 2000;133:592-9.

12. Lonardo A, Adinolfi LE, Petta S, Craxi A and Loria P. Hepatitis C and diabetes: the inevitable coincidence? Expert Review of Anti-Infective Therapy 2009;7(3):293-308.

13. Negro F and Alaei M. Hepatitis $C$ virus and type 2 diabetes. World Journal of Gastroenterology, 2009;15(13):1537-1547.

14. Younossi ZM, Stepanova M, Nader F, Younossi Z and Elsheikh E. Associations of chronic hepatitis C with metabolic and cardiac outcomes. Alimentary Pharmacology \& Therapeutics 2013;37(6):647-652.

15. Naing C, Mak JW, Ahmed SI and Maung M. Relationship between hepatitis $\mathrm{C}$ virus infection and type 2 diabetes mellitus: meta-analysis. World Journal of Gastroenterology 2012;18(14):1642-1651.

16. Allison MED, Wreghitt T, Palmer CR and Alexander GJM, Evidence for a link between hepatitis $\mathrm{C}$ virus infection and diabetes mellitus in a cirrhotic population, Journal of Hepatology, 1994;21(6):1135-1139.

17. Lecube A, Herna'ndez C, Genesca J and Simo R. Glucose abnormalities in patients with hepatitis $\mathrm{C}$ virus infection: epidemiology and pathogenesis. Diabetes Care, 2006;29(5):1140-1149.

18. Elhawary EI, Mahmoud GF, El-Daly MA, Mekky FA, Esmat GG and Abdel-Hamid M. Association of HCV with diabetes mellitus: an Egyptian case -control study. Virology Journal, 2011;8:367.

19. Pearlman BL and Traub N. Sustained virologic response to antiviral therapy for chronic hepatitis $\mathrm{C}$ virus infection: a cure and so much more. Clinical Infectious Diseases 2011;52(7):889-900.

20. Mukherjee et al. Occurrence of type 2 diabetes in chronic liver diseases. International Journal of Medicine and Public Health. 2013;3:44 -47.

21. Ashwani et al. Prevalence of and factors affecting type 2 diabetes mellitus in chronic liver disease. The Saudi Journal of gastroenterology. 2008;3:118 -21.

22. Knobler C, Schihmanter R, Zifroni A, Fenakel G, Increased risk of type $2 \mathrm{DM}$ in Non-cirrhotic patients with chronic hepatitis C virus infection, Myo Clin Proc., 2000;75(4):355359.

23. Mujeeb SA, Aamir K, Mehmood K. Seroprevalence of HBV, $\mathrm{HCV}$ and HIV Infections among College Going first time Voluntary Blood Donors. JPMA, 2000;50:269.

24. Caronia S, Taylor K, Pagliaro L, Can C, Palazzo U, Petrik J, Orahilly S, Shore S, Tom BDN and Alexander GJM. Further Evidence for an Association Between Non - Insulin- 
Dependent Diabetes Mellitus and Chronic Hepatitis C Virus Infection. Hepatology,1999;30:1059-1063.

25. Mahtab MA., Rahman S., Foster G., Khan M., Karim M. F., Solaiman S. Epidemiology of Hepatitis B Virus in Bangladeshi General Population. Hepato-Bìlia,y and Pancreatic Diseases International, 2008;7(6):595-600.

26. Li-Ng M, Tropp S, Danoff A, Bini EJ. Association between chronic hepatitis $\mathrm{B}$ virus infection and diabetes among Asian Americans and Pacific Islanders. Digestive and Liver Disease,2007;39:549—556.

27. Moscatiello S, Manini R, Marchesini G. Diabetes and liver disease. An ominous association. Nutrition, Metabolism Cardiovascular Dis 2007;17:63 -70.

28. Kobashi-Margain RA et al. Prevalence of type 2 diabetes mellitus and chronic liver disease: A retrospective study of the association of two increasingly common diseases in Mexico. Ann Heptol 2010;9:282-8.

29. Alavian SM, Hajarizadeh B, Nematizadeh F, Larijani B. Prevalence and det erminants of diabetes mellitus among Iranian patients with chronic liver disease. BMC endocrine Disorder 2004;4:4.

30. Garcia-Compean D, Jaquez-Quintana JO, Maldonado-Garza H. Hepatogenous diabetes: Current views of an ancient problem. Ann Hepatol 2009;8 :13-20.
31. Mason AL, Lau JY, Hoang $\mathrm{N}$ et al. Association of diabetes mellitus and chronic hepatitis C infection. Hepatology 1999;29:328-33.

32. Qureshi H, Ahsan T, Mujeeb SA, Jawad F, Mehdi I, Ahmed $\mathrm{W}$, et al. Diabetes mellitus is equally frequent in chronic HCV and HBV infection, J Pak Med Assoc 2002;52:280 -3.

33. White L, Ratziu V and El-Serag HB. Hepatitis C infection and risk of diabetes: a systematic review and meta-analysis, Journal of Hepatology. 2008;49 (5):831 -844.

34. Ali, S. Abera, A. Mihret, and T. Abebe. Association of hepatitis $\mathrm{C}$ virus infection with type II diabetes in Ethiopia: a hospital-based case-control study, Interdisciplinary Perspectives on Infectious Diseases. 2012;7:2012.

35. Hsieh PS and Hsieh YJ. Impact of liver diseases on the development of type 2 diabetes mellitus, World Journal of Gastroenterology, 2011;17 (48):5240 -5245.

36. Stepanova, Lam B, Younossi Y, Srishord MK and Younossi $\mathrm{ZM}$. Association of hepatitis $\mathrm{C}$ with insulin resistance and type 2 diabetes in US general population: the impact of the epidemic of obesity, Journal of Viral Hepatitis. 2012; 19(5):341 -345.

37. Chiquete, Ochoa-Guzmán A, García-Lamas L et al. Hepatitis $\mathrm{C}$ virus infection and type 2 diabetes mellitus in Mexican patients, Revista Médica del Instituto Mexicano del Seguro Social, 2012;50 (5):481-486. 